\title{
MODEL MATEMATIKA GERAK PENDULUM DENGAN MEMPERTIMBANGKAN GAYA GESEK UDARA
}

\author{
Rukmono Budi Utomo \\ Universitas Muhammadiyah Tangerang \\ Email: rukmono.budi.u@mail.ugm.ac.id
}

\begin{abstract}
This paper aims to construct a mathematical model of the pendulum motion by considering the frictional force of air. The study was conducted by first making a pendulum motion illustration with a length of rope $l$ and pendulum mass $m$ vertically that given deviation and speed. Based on that created a mathematical model of motion of the pendulum and its determination to find out the time $t$ it takes the pendulum passing through the zero point and the current time there is no change in the speed deviation of the pendulum. In this study will also be given a simulation of mathematical models that have been made.
\end{abstract}

Keywords: Pendulum Motion Mathematical Model, Air Friction

\begin{abstract}
ABSTRAK. Tulisan ini bertujuan untuk mengkonstruksikan model matematika dari gerak pendulum dengan mempertimbangkan adanya gaya gesek udara. Penelitian dilakukan dengan terlebih dahulu membuat ilustrasi gerak pendulum sederhana dengan panjang tali $l$ dan beban massa pendulum $m$ yang diikatkan secara vertikal dan diberikan simpangan serta kecepatan. Berdasarkan hal tersebut dibuat model matematis gerak pendulum beserta penentuan $t$ untuk mengetahui waktu yang diperlukan pendulum melewati titik nol dan waktu saat tidak ada perubahan kecepatan simpangan pendulum. Dalam penelitian ini juga akan diberikan simulasi perhitungan dari model matematis yang telah dibuat.
\end{abstract}

Kata Kunci: Model Matematis Gerak Pendulum, Gesekan Udara

\section{PENDAHULUAN}

Pendulum atau bandul merupakan benda yang terikat pada sebuah tali dan dapat berayun secara bebas dan periodik. Suatu pendulum sederhana tersusun atas sebuah bandul bermassa $m$ yang diikat dengan tali dengan panjang $l$ dan ditempatkan menggantung vertikal ke bawah.

Saat tidak diberikan perlakukan apapun, dapat dikatakan bahwa pendulum berada pada posisi diam atau posisi nol. Pada posisi ini dikatakan bahwa simpangan pendulum $\theta$ adalah nol. Lebih lanjut ketika pendulum ditarik, maka 
pendulum memiliki nilai simpangan tertentu. Nilai simpangan ini dapat berupa positif $\theta>0$ ataupun negatif $\theta<0$.

Lebih lanjut apabila pendulum diberikan suatu kecepatan tertentu $\dot{\theta}$ baik dengan cara diayunkan (arah kiri) $\dot{\theta}<0$ ataupun didorong terlebih dahulu ke belakang (arah kanan) $\dot{\theta}>0$, maka yang menjadi pertanyaan selanjutnya adalah bagaimana menjelaskan perilaku gerakan pendulum tersebut dalam suatu model matematika? Apabila pada gerak pendulum berlaku gaya gesek udara seperti keadaan sebenarnya, bagaimana model matematikanya? Selanjutnya bagaimana cara menentukan waktu agar pendulum melewati titik nol? Serta kapan waktu yang menunjukkan tidak ada perubahan kecepatan pendulum? Serangkaian perrtanyaan di atas akan coba penulis ulas dalam penelitian ini. Dalam penelitian ini juga, peneliti tidak hanya mengkonstruksikan model matematis gerak pendulum, namun juga dilakukan simulasi terhadap model yang telah terbentuk dengan memasukan beberapa nilai parameter yang terkait.

Penelitian mengenai gerakan pendulum yang dilakukan oleh peneliti bukanlah yang pertama kalinya. Awal mula studi tentang pendulum ini diawali dengan teori hukum Hooke tentang gaya pemulih pada pegas. Hukum Hook sendiri telah dikaji dan dibahas secara lengkap oleh (Rychlewski, 1984) pada artikelnya yang berjudul On Hook's Law.

Penelitian tentang gerakan pendulum juga dilakukan oleh (Kecik et.al, 2006)-yakni tentang Chaos pada gerakan pendulum sebagai sistem dengan parametrik resonansi. Selain itu, (Kecik et.al, 2012) juga meneliti gerakan autoparametrik dari sistem nonlinear pendulum. Penelitian serupa tentang gerakan pendulum juga telah dilakukan oleh (Leeet.al, 1994) dengan topik penelitian tentang analisis global dari sistem gerakan harmonik pendulum dengan internal resonansi

\section{METODE PENELITIAN}

Metode yang dilakukan dalam penelitian ini adalah dengan studi pustaka, yakni dengan memperlajari terlebih dahulu teori tentang gerakan pendulum melalui buku Agarwal (2008), Boyce (1992), Haberman (1971), Perko (2000), 
Wiggins (2003) serta buku-buku lain yang dapat dibaca dalam daftar pustaka. Selain buku, beberapa artikel atau jurnal juga digunakan sebagai referensi dalam penelitian ini, antara lain artikel J. Rychlewski (1984), Kecik, K., dan Warminski, J (2012), Lee, W.K. dan Hsu, C.S. (1994) dan jurnal lain yang dapat dibaca dalam daftar pustaka.

\section{HASIL DAN PEMBAHASAN}

\subsection{Model dan Penyelesaian}

Diberikan pendulum sederhana dengan panjang tali $l$ dan massa bandul $m$ yang diikatkan secara vertikal menggantung ke bawah. Mula-mula pendulum tersebut berada pada posisi diam atau posisi nol sampai diberikan simpangan $\theta$ kecepatan simpangan $\dot{\theta}$ sehingga berosilasi seperti pada gambar berikut ini.

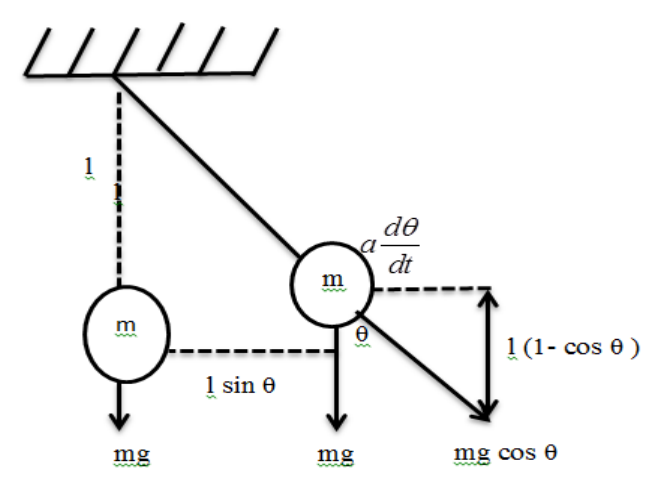

Gambar 1. Pendulum berosilasi

Ketika pendulum diikat secara vertikal menggantung ke bawah seperti pada gambar 1 di atas, maka secara alamiah massa pendulum $m$ akan mendapat pengaruh gaya gravitasi $g$. Lebih lanjut, ketika pendulum mulai diayunkan dengan cara ditarik, maka terdapat besarnya sudut pergerakan pendulum $\theta$ yang dikenal dengan simpangan pendulum. Nilai $\theta$ dianggap bernilai positif apabila pendulum ditarik ke arah kanan, dan sebaliknya bernilai negatif apabila pendulum ditarik ke arah kiri. Sebelum diayunkan, didefinsikan $\dot{\theta}$ yang merupakan kecepatan pendulum. Nilai $\dot{\theta}$ ini juga dapat berupa nilai positif ataupun negatif tergantung cara memberikan kecepatan pada pendulum tersebut (didorong atau 
ditarik). Saat pendulum bergerak, maka pergerakan pendulum akan mendapatkan gaya gesek udara yang merupakan gaya redam dan disimbolkan dengan $a \frac{d \theta}{d t}$.

Sebagaimana diketahui bahwa gaya gesek ataupun gaya redam selalu berlawanan dengan arah gerakan pendulum itu sendiri sebagaimana hukum Hooke menjelaskan tantang gaya gesek lantai yang berlawanan terhadap tarikan maupun dorongan pada pegas secara horizontal.

Dalam penelitian ini diasumsikan bahwa mula-mula pegas akan ditarik ke arah kanan sehingga nilai simpangan pendulum $\theta$ adalah positif. Lebih lanjut, kecepatan yang diberikan pada pendulum juga dalam hal ini dimisalkan positif yakni $\frac{d \theta}{d t}>0$ yang memberi arti bahwa pendulum diperlakukan tarikan atau gerakan ke arah kanan dan bukan berupa dorongan. Berdasarkan hal tersebut, model matematis gerak pendulum sebagaimana diilustrasikan pada gambar $1 \mathrm{di}$ atas dapat dituliskan sebagai berikut :

$$
m l \ddot{\theta}+a \dot{\theta}+m g \sin \theta=0
$$

Karena $\dot{\theta}=\frac{d \theta}{d t}$ yang merupakan kecepatan dari gerak pendulum dan $\ddot{\theta}=\frac{d^{2} \theta}{d t}$ yang merupakan percepatan gerak pendulum, maka berdasarkan hal tersebut persamaan (1) dapat dituliskan kembali sebagai berikut :

$$
m l \frac{d^{2} \theta}{d t}+a \frac{d \theta}{d t}+m g \sin \theta=0
$$

Apabila didefinisikan $\psi=\frac{a}{m l}$ dan $\omega=\frac{g}{l}$, maka persamaan (2)di atas dapat dituliskan sebagai berikut

$$
\frac{d^{2} \theta}{d t}+\psi \frac{d \theta}{d t}+\omega \sin \theta=0
$$

Misalkan $x_{1}=\theta$ dan $x_{2}=\dot{\theta}$, maka model persamaan (3) dapat dituliskan kembali sebagai sistem model simutan sebagai berikut 


$$
\begin{aligned}
& \dot{x}_{1}=x_{2} \\
& \dot{x}_{2}=-\omega \sin x_{1}-\psi x_{2}
\end{aligned}
$$

Titik kesetimbangan $\left(x_{1}, x_{2}\right)$ dari sistem (4) diperoleh dengan menyamadengankan nol $\dot{x}_{1}$ dan $\dot{x}_{2}$, dan berdasarkan hal tersebut diperoleh titik kesetimbangan sistem (4) yakni $(0,0)$ dan $(n \pi, 0)$ dengan $n \in N$.

Karena sistem(4)merupakan model sistem nonlinear, maka akan dilakukan linearisasi sistem disekitar titik kesetimbangan (equilibrium). Linearisasi dilakukan dengan Jakobian, dan berdasarkan hal tersebut diperoleh sistem sebagai berikut

$$
D f\left(x_{1}, x_{2}\right)=\left[\begin{array}{ll}
\frac{\partial f_{1}\left(x_{1}, x_{2}\right)}{\partial x_{1}} & \frac{\partial f_{1}\left(x_{1}, x_{2}\right)}{\partial x_{2}} \\
\frac{\partial f_{2}\left(x_{1}, x_{2}\right)}{\partial x_{1}} & \frac{\partial f_{2}\left(x_{1}, x_{2}\right)}{\partial x_{2}}
\end{array}\right]\left[\begin{array}{l}
x_{1} \\
x_{2}
\end{array}\right]=\left[\begin{array}{cc}
0 & 1 \\
-\omega \cos x_{1} & -\psi
\end{array}\right]\left[\begin{array}{l}
x_{1} \\
x_{2}
\end{array}\right]
$$

dengan $f_{1}\left(x_{1}, x_{2}\right)=x_{2}$ dan $f_{2}\left(x_{1}, x_{2}\right)=-\omega \sin x_{1}-\psi x_{2}$.

Selanjutnya akan dilakukan analisis kestabilan terhadap sistem model terlinearisasi disekitar titik kesetimbangan $(0,0)$ dan untuk analisis disekitar titik kesetimbangan $(n \pi, 0)$, dapat dilakukan dengan cara dan langkah yang sama. Berdasarkan sistem linearisasi pendulum sesuai persamaan (5), maka analisis kestabilan sistem model terlinerisasi disekitar titik kesetimbangan $(0,0)$ dapat diuraikan sebagai berikut:

$$
D f(0,0)=\left[\begin{array}{cc}
0 & 1 \\
-\omega & -\psi
\end{array}\right]\left[\begin{array}{l}
x_{1} \\
x_{2}
\end{array}\right]
$$

Selanjutnya nilai eigen dari sistem (6) diperoleh nilai-nilai eigen sebagai berikut

$$
\lambda_{1,2}=\frac{-\psi}{2} \pm \frac{\sqrt{\psi^{2}-4 \omega}}{2}
$$


Solusi $x_{1}(t)$ dan $x_{2}(t)$ dari sistem (6) berdasarkan nilai eigen (7) masing-masing dituliskan sebagai berikut:

$$
\begin{gathered}
x_{1}(t)=C_{1} e^{\left(\frac{-\psi}{2}+\frac{\sqrt{\psi^{2}-4 \omega}}{2}\right) t}+C_{2} e^{\left(\frac{-\psi}{2}-\frac{\sqrt{\psi^{2}-4 \omega}}{2}\right) t} \\
x_{2}(t)=\left(\frac{-\psi}{2}+\frac{\sqrt{\psi^{2}-4 \omega}}{2}\right) C_{1} e^{\left(\frac{-\psi}{2}+\frac{\sqrt{\psi^{2}-4 \omega}}{2}\right) t}+\left(\frac{-\psi}{2}-\frac{\sqrt{\psi^{2}-4 \omega}}{2}\right) C_{2} e^{\left(\frac{-\psi}{2}-\frac{\sqrt{\psi^{2}-4 \omega}}{2}\right) t}
\end{gathered}
$$

Berdasarkan nilai-nilai eigen pada persamaan (7) di atas, dapat dikaji tiga kondisi berdasarkan $\sqrt{\psi^{2}-4 \omega}$ yang selanjutnya dijelaskan sebagai berikut:

1) Kondisi $\sqrt{\psi^{2}-4 \omega}=0$

Apabila nilai $\sqrt{\psi^{2}-4 \omega}=0$, maka diperoleh nilai eigen sistem (6) $\lambda_{1}=\lambda_{2}=\frac{-\psi}{2}$. Dengan mengingat bahwa $\psi=\frac{a}{m l}>0$, maka $\frac{-\psi}{2}<0$.

Berdasarkan hal tersebut solusi matematis $x_{1}(t)$ dan $x_{2}(t)$ berdasarkan kondisi 1 ini dapat dituliskan sebagai berikut

$$
\begin{gathered}
x_{1}(t)=C_{1} e^{\frac{-\psi}{2} t}+C_{2} t e^{\frac{-\psi}{2} t} \\
x_{2}(t)=\frac{-\psi}{2} C_{1} e^{\frac{-\psi}{2} t}+C_{2} e^{\frac{-\psi_{t}}{2} t}+\frac{-\psi}{2} t C_{2} e^{\frac{-\psi_{t}}{2} t}
\end{gathered}
$$

Dengan syarat awal $x_{1}(0)=x_{10}$ dan $x_{2}(0)=x_{20}$, maka solusi $(10)$ dan (11) masing-masing dapat dituliskan kembali sebagai berikut

$$
\begin{aligned}
& x_{1}(t)=x_{10}\left(e^{\frac{-\psi}{2} t}+\frac{\psi}{2} t e^{\frac{-\psi}{2} t}\right)+x_{20} t e^{\frac{-\psi}{2} t} \\
& x_{2}(t)=-\frac{\psi^{2}}{4} t e^{\frac{-\psi}{2} t} x_{10}+\left(e^{\frac{-\psi_{t}}{2}}-\frac{\psi}{2} t e^{\frac{-\psi_{t}}{2}}\right) x_{20}
\end{aligned}
$$

Lebih lanjut berdasarkan solusi (12) dan (13) akan ditentukan waktu agar pendulum berada pada titik nol dan waktu ketika tidak terdapat perubahan kecepetan pendulum. Masing-masing waktu tersebut dicari dengan 
menyamadengankan nol $x_{1}(t)$ dan $x_{2}(t)$ sehingga berdasarkan hal tersebut diperoleh waktu $t_{1}=\frac{x_{10}}{\frac{-\psi}{2} x_{10}-x_{20}}$ dan $t_{2}=\frac{x_{20}}{\frac{\psi^{2}}{4} x_{10}+\frac{\psi}{2} x_{20}}$.

Masing-masing nilai $t_{1}$ dan $t_{2}$ akan ada apabila $\frac{-\psi}{2} x_{10}>x_{20}$ dan $\frac{\psi^{2}}{4} x_{10}>-\frac{\psi}{2} x_{20}$

2) Kondisi $\sqrt{\psi^{2}-4 \omega}>0$

Apabila nilai $\sqrt{\psi^{2}-4 \omega}>0$, maka diperoleh nilai eigen sistem (6) $\lambda_{1}=\frac{-\psi}{2}+\frac{\sqrt{\psi^{2}-4 \omega}}{2}$ dan $\lambda_{2}=\frac{-\psi}{2}-\frac{\sqrt{\psi^{2}-4 \omega}}{2}$ dengan $\lambda_{2}<\lambda_{1}<0$.

Berdasarkan hal tersebut solusi matematis $x_{1}(t)$ dan $x_{2}(t)$ berdasarkan kondisi 2 ditunjukkan dengan persamaan (8) dan (9). Dengan syarat awal $x_{1}(0)=x_{10}$ dan $x_{2}(0)=x_{20}$, maka solusi (8) dan (9) masing-masing dapat dituliskan kembali sebagai berikut

$$
\begin{array}{r}
x_{1}(t)=\frac{1}{\lambda_{2}-\lambda_{1}}\left[\left(\lambda_{2} x_{10}-x_{20}\right) e^{\lambda_{1} t}+\left(x_{20}-\lambda_{1} x_{10}\right) e^{\lambda_{2} t}\right] \\
x_{2}(t)=\frac{1}{\lambda_{2}-\lambda_{1}}\left[\left(\lambda_{1} \lambda_{2} e^{\lambda_{1} t}-\lambda_{1} \lambda_{2} e^{\lambda_{2} t}\right) x_{10}+\left(\lambda_{2} e^{\lambda_{2} t}-\lambda_{1} e^{\lambda_{1} t}\right) x_{20}\right]
\end{array}
$$

Lebih lanjut berdasarkan solusi (14) dan (15) waktu agar pendulum berada pada titik nol dan waktu ketika tidak terdapat perubahan kecepetan pendulum adalah $\quad t_{1}=\frac{1}{\lambda_{2}-\lambda_{1}} \ln \left(\frac{\lambda_{2} x_{10}-x_{20}}{\lambda_{1} x_{10}-x_{20}}\right) \quad$ dan $t_{2}=\frac{1}{\lambda_{2}-\lambda_{1}} \ln \left(\frac{\lambda_{1} \lambda_{2} x_{10}-\lambda_{1} x_{20}}{\lambda_{1} \lambda_{2} x_{10}-\lambda_{1} x_{20}}\right)$. Kedua waktu $t_{1}$ dan $t_{2}$ akan ada apabila $\frac{\lambda_{2} x_{10}-x_{20}}{\lambda_{1} x_{10}-x_{20}}>1$ dan $\frac{\lambda_{1} \lambda_{2} x_{10}-\lambda_{1} x_{20}}{\lambda_{1} \lambda_{2} x_{10}-\lambda_{1} x_{20}}>1$

3) Kondisi $\sqrt{\psi^{2}-4 \omega}<0$ 
Apabila nilai $\sqrt{\psi^{2}-4 \omega}<0$, maka nilai eigen sistem (6) adalah imajiner yakni $\lambda_{1}=\alpha+i \beta$ dan $\lambda_{2}=\alpha-i \beta$ dengan $\alpha=-\frac{\psi}{2}$ dan $\beta=\frac{\sqrt{\psi^{2}-4 \omega}}{2}$.

Berdasarkan hal tersebut solusi matematis $x_{1}(t)$ dan $x_{2}(t)$ dengan syarat awal $x_{1}(0)=x_{10}$ dan $x_{2}(0)=x_{20}$ berdasarkan kondisi 3 dituliskan kembali sebagai berikut

$$
\begin{gathered}
x_{1}(t)=-x_{10} \frac{\alpha e^{\alpha}}{\beta} \sin \beta t+x_{20} \frac{e^{\alpha}}{\beta} \sin \beta t \\
x_{2}(t)=-x_{10} \frac{\left(\alpha^{2}+\beta^{2}\right) e^{\alpha}}{\beta} \sin \beta t+x_{20} \frac{e^{\alpha}}{\beta}(\alpha \sin \beta t+\beta \cos \beta t)
\end{gathered}
$$

Lebih lanjut berdasarkan solusi (16) dan (17) waktu agar pendulum berada pada titik nol dan waktu ketika tidak terdapat perubahan kecepetan pendulum. $\quad t_{1}=\frac{1}{\beta} \arctan \left(\frac{-\beta x_{10}}{x_{20}-\alpha x_{10}}\right)$ dan $t_{2}=\frac{1}{\beta} \arctan \left(\frac{-\beta x_{20}}{\left(\alpha^{2}+\beta^{2}\right) x_{10}-\alpha}\right)$

Kedua waktu $t_{1}$ dan $t_{2}$ akan ada apabila periode $\frac{-\beta x_{10}}{x_{20}-\alpha x_{10}}$ dan $\frac{-\beta x_{20}}{\left(\alpha^{2}+\beta^{2}\right) x_{10}-\alpha}$ bukan $\frac{\pi}{2}$ atau kelipatannya.

\subsection{Simulasi}

Simulasi dilakukan untuk tiap kondisi yang dibahas pada penelitian ini, dan masing-masing dijelaskan pada uraian di bawah ini

1) Kondisi $\sqrt{\psi^{2}-4 \omega}=0$

Ada banyak sekali nilai parameter $\psi$ dan $\omega$ agar nilai $\sqrt{\psi^{2}-4 \omega}=0$, namun pada intinya kondisi ini terjadi apabila nilai $\psi^{2}=4 \omega$. Sebagai 
pengingat bahwa nilai $\psi=\frac{a}{m l}$ dan $\omega=\frac{g}{l}$, dan misalkan dalam hal ini di ambil parameter $a=20, m=1, l=10$ dan $g=10 \mathrm{~m} / \mathrm{s}^{2}$ atau $\psi=2$ dan $\omega=1$ dan dengan kondisi awal $x_{1}(0)=x_{2}(0)=10$. Berdasarkan hal tersebut diperoleh simulasi sebagai berikut.

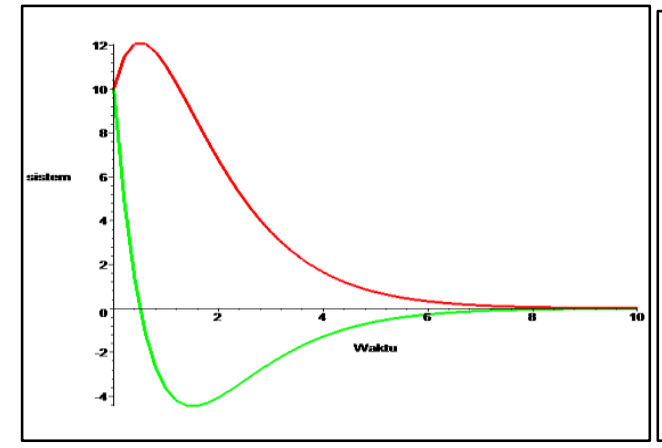

Gambar 2. Plot $x_{1}(t)$ dan $x_{2}(t)$ Sistem (6) kondisi 1

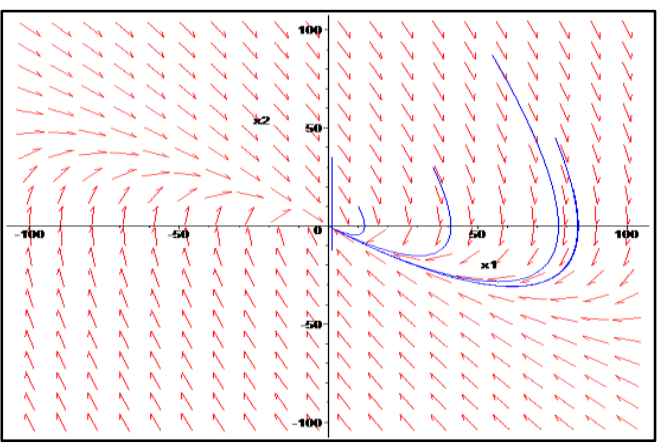

Gambar 3. Potret fase Sistem (6) kondisi 1

Gambar 2 diatas menunjukkan grafik plot sistem pendulum terlinearisasi di sekitar titik kesetimbangan $(0,0)$. Grafik berwarna merah menunjukkan simpangan atau posisi pendulum $x_{1}(t)=\theta$ dan garfik berwarna hijau menunjukkan kecepatan pendulum $x_{2}(t)=\dot{\theta}$.

Dari gambar 2 terlihat bahwa pendulum yang digerakan suatu saat akan berhenti dengan kata lain simpangan $\theta$ dan kecepatan $\dot{\theta}$ akan habis atau nol. Hal demikian dapat terjadi karena adanya gaya gesekan udara $a \frac{d \theta}{d t}$ dengan nilai konstanta gaya sesek udara dalam simulasi ini ditetapkan $a=20$.

Lebih lanjut gambar 3 menunjukkan potret fase sistem (6) dengan nilai parameter yang diberikan pada kondisi 1 ini. Potret fase pada gambar 3 menunjukkan bahwa titik kesetimbangan $(0,0)$ stabil asimptotik dengan 
tipe sink. Kestabilan asimptotik ini diperkuat dengan nilai eigen kondisi 1 yakni $\lambda_{1}=\lambda_{2}=\frac{-\psi}{2}<0$.

2) Kondisi $\sqrt{\psi^{2}-4 \omega}>0$

Agar terbentuk kondisi $\sqrt{\psi^{2}-4 \omega}>0$, misalkan dalam hal ini di ambil parameter $a=20, m=0.5, l=10$ dan $g=10 m / s^{2}$ atau $\psi=4$ dan $\omega=1$ dan dengan kondisi awal $x_{1}(0)=x_{2}(0)=10$. Berdasarkan hal tersebut diperoleh simulasi sebagai berikut

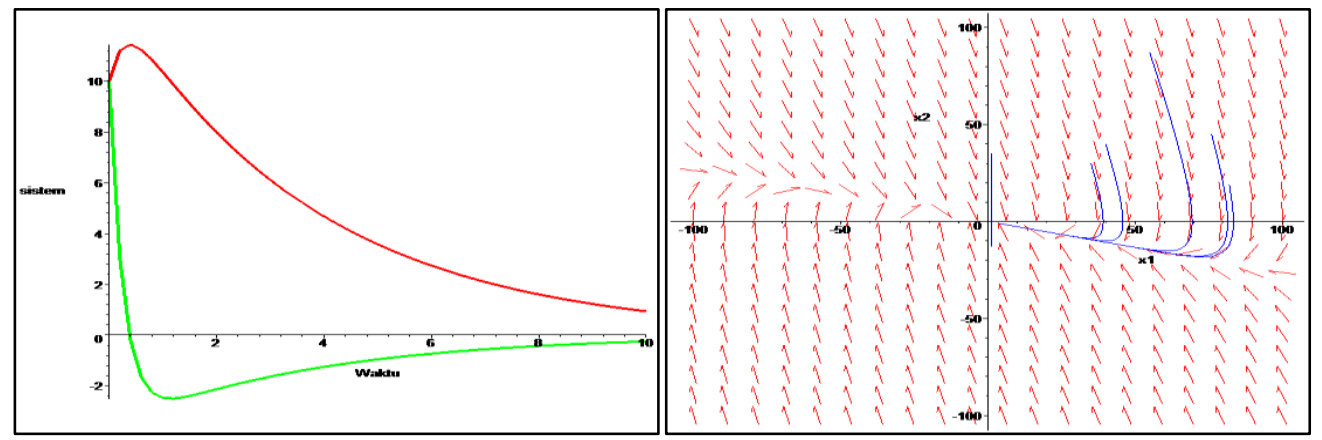

Gambar 4. Plot $x_{1}(t)$ dan $x_{2}(t)$ Sistem (6) kondisi 2

Gambar 5. Potret fase Sistem (6) kondisi 2

Gambar 4 diatas menunjukkan grafik plot sistem pendulum terlinearisasi di sekitar titik kesetimbangan $(0,0)$. Grafik berwarna merah menunjukkan simpangan atau posisi pendulum $x_{1}(t)=\theta$ dan garfik berwarna hijau menunjukkan kecepatan pendulum $x_{2}(t)=\dot{\theta}$. Dari gambar 4 terlihat bahwa pendulum yang digerakan suatu saat akan berhenti dengan kata lain simpangan $\theta$ dan kecepatan $\dot{\theta}$ akan habis atau nol. Hal demikian dapat terjadi karena adanya gaya gesekan udara $a \frac{d \theta}{d t}$ dengan nilai konstanta gaya sesek udara dalam simulasi ini ditetapkan $a=20$. Meski pendulum akan berhenti sebagimana pada kondisi 1, namun 
perilaku pendulum menuju berhenti sangatlah berbeda. Perbedaan ini dapat dilihat pada potret fase gambar 5.

Potret fase sistem (6) sebegaimana ditunjukkan gambar 6 menunjukkan titik kesetimbangan $(0,0)$ stabil asimptotik dengan tipe node. Tipe ini berbeda dengan potret fase kondisi 1 yang bertipe node. Kestabilan asimptotik ini diperkuat dengan nilai eigen kondisi 2 yakni $\lambda_{1}=\frac{-\psi}{2}+\frac{\sqrt{\psi^{2}-4 \omega}}{2}$ dan $\lambda_{2}=\frac{-\psi}{2}-\frac{\sqrt{\psi^{2}-4 \omega}}{2}$ dengan $\lambda_{2}<\lambda_{1}<0$

3) Kondisi $\sqrt{\psi^{2}-4 \omega}<0$

Agar terbentuk kondisi $\sqrt{\psi^{2}-4 \omega}<0$, misalkan dalam hal ini di ambil parameter $a=20, m=2, l=10$ dan $g=10 m / s^{2}$ atau $\psi=1$ dan $\omega=1$ dan dengan kondisi awal $x_{1}(0)=x_{2}(0)=10$. Berdasarkan hal tersebut diperoleh simulasi sebagai berikut:

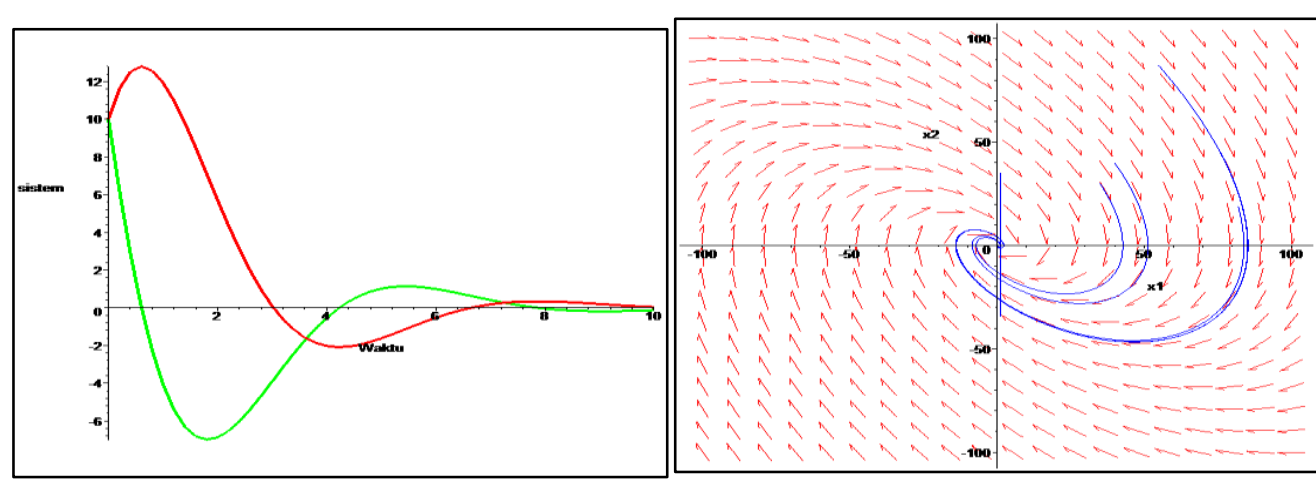

Gambar 6. Plot $x_{1}(t)$ dan $x_{2}(t)$ Gambar 7. Potret fase Sistem (6) Sistem (6) kondisi 3 Kondisi 3

Gambar 6 diatas menunjukkan grafik plot sistem pendulum terlinearisasi di sekitar titik kesetimbangan $(0,0)$. Grafik berwarna merah menunjukkan simpangan pendulum $x_{1}(t)=\theta$ dan garfik berwarna hijau menunjukkan kecepatan pendulum $x_{2}(t)=\dot{\theta}$. Dari gambar 6 terlihat 
bahwa pendulum yang digerakan suatu saat akan berhenti atau dengan kata lain simpangan $\theta$ dan kecepatan $\dot{\theta}$ akan habis atau nol. Hal demikian dapat terjadi karena adanya gaya gesekan udara $a \frac{d \theta}{d t}$ dengan nilai konstanta gaya sesek udara dalam simulasi ini ditetapkan $a=20$. Cara pendulum ini berhenti berbeda dengan cara pendulum berhenti pada kondisi 1 dan 2. Pada kondisi 3 ini sebelum pendulum berhenti, terlebih dahulu pendulum akan berosilasi. Hal ini dikarenakan nilai eigen yang bernilai imajner. Berdasarkan hal ini pula, potret fase yang ditunjukkan pada gambar 7 menjelaskan bahwa titik $(0,0)$ stabil asimptotik dengan tipe potert fase adalah spiral

\section{KESIMPULAN DAN SARAN}

Terdapat beberapa kesimpulan dan saran dalam penelitian ini ynag masing-masing diuraikan sebagai berikut.

\subsection{Kesimpulan}

Kesimpulan yang diperoleh adalah :

1) Model matematika yang menjelaskan gerakan pendulum dengan adanya gaya gesek udara ditunjukkan pada persamaan (1) atau (4) dengan sistem yang telah terlinierisasi disekitar titik kesetimbangan $(0,0)$ ditunjukkan pada persamaan $(6)$ dengan solusi $x_{1}(t)$ dan $x_{2}(t)$ sistem(6) ditunjukkan pada persamaan (8) dan (9).

2) Nilai eigen dari sistem (6) memberikan nilai $\lambda_{1,2}=\frac{-\psi}{2} \pm \frac{-}{2} \sqrt{\psi^{2}-4 \omega}$

3) Berdasarkan nilai eigen pada poin 2 diatas, dibagi tiga kondisi berdasarkan nilai $\sqrt{\psi^{2}-4 \omega}$, yakni kondisi saat $\sqrt{\psi^{2}-4 \omega}=0$, kondisi saat $\sqrt{\psi^{2}-4 \omega}>0$ dan $\sqrt{\psi^{2}-4 \omega}<0$ 
4) Untuk kondisi $\sqrt{\psi^{2}-4 \omega}=0$, solusi $x_{1}(t)$ dan $\quad x_{2}(t)$ sistem ditunjukkan pada persamaan (12) dan (13)dengan waktu pendulum mencapai titik nol $t_{1}$ dan waktu saat tidak terdapat perubahan kecepatan pendulum $t_{2}$ yang dapat dilihatpada pembahasan kondisi 1

5) Untuk kondisi $\sqrt{\psi^{2}-4 \omega}>0$, solusi $x_{1}(t)$ dan $x_{2}(t)$ sistem ditunjukkan pada persamaan (14) dan (15) dengan waktu pendulum mencapai titik nol $t_{1}$ dan waktu saat tidak terdapat perubahan kecepatan pendulum $t_{2}$ yang dapat dilihat pada pembahasan kondisi 2

6) Untuk kondisi $\sqrt{\psi^{2}-4 \omega}<0$, solusi $x_{1}(t)$ dan $x_{2}(t)$ sistem ditunjukkan pada persamaan (16)dan (17)dengan waktu pendulum mencapai titik nol $t_{1}$ dan waktu saat tidak terdapat perubahan kecepatan pendulum $t_{2}$ yang dapat dilihat pada pembahasan kondisi 3

7) Berdasarkan simulasi yang dilakukan untuk ketiga kondisi di atas, terlihat bahwa pendulum yang digerakan dengan diberikan simpangan dan kecepatan suatu saat pendulum tersebut akan berhenti. Perilaku pendulum menuju berhentinya untuk masing-masing kondisi berbeda-beda tergantung nilai eigenya dan dapat dilihat pada pembahasan simulasi.

\subsection{Saran}

Saran yang dapat diberikan adalah :

1) Perlu dilakukan simulasi terhadap kondisi 3 saat nilai eigen sistem (6) adalah imajiner murni.

2) Perlu diselidiki linearisasi sistem (4) disekitar titik kesetimbangan $(n \pi, 0)$ dengan $n=1,2, \ldots$.

3) Perlu dikembangkan sistem model matematis gerak pendulum dengan mempertimbangan faktor lain yang terjadi pada kehidupan sebenarnya

4) Perlu dikembangkan model matematis gerak pendulum 3 Dimensi. 


\section{UCAPAN TERIMAKASIH}

Ucapan terimakasih ditujukan kepada kampus Universitas Muhammadiyah Tangerang dan kampus Institut Teknologi Bandung atas support sehingga tulisan ini dapat selesai dan penulis dapat mengikuti seminar nasional matematika dan terapannya di kampus Universitas Jendral Soedirman Tanggal 3 Desember 2016

\section{DAFTAR PUSTAKA}

Agarwal, R. D, dan Regan, D. O., An Introduction to Differential Equation, Springer, New York, 2008.

Boyce, W.E. dan Richard, Elementary Differential Equation and Boundary Value Problem, fifth edition, John Wiley and Sons, Inc., 1992.

Haberman, R., Mathematical Models : Mechanical Vibration, Population Dynamics and Traffic Flow, Prentice Hall, Inc., 1971.

Kecik, K., dan Warminski, J. Chaos in Mechanical Pendulum-Like System near Main Parametric Resonance, Procedia IUTAM, 5 (2012), 249-258.

Lee, W.K. dan Hsu, C.S., A Global Analysis of an Harmonically Excited SpringPendulum System with Internal Resonance, Journal of Sound and Vibration, 171(3) (1994), 335-359.

Perko, Lawrence., Differensial Equation and Dynamical System, Third Edition, Springer-Verlag, New York, 2000.

Rychlewski, J., On Hook's Law, Pergamon Press, Ltd., PMM U.S.S.R., 48(3) 1984, 303-314.

Warminski, J. dan Kecik, K. Autoparametric Vibration of Nonlinear System with Pendulum, Mathematical Problems in Engineering Volume 2006, 2006, Article ID 80705, 19 pages, http://dx.doi.org/10.1155/MPE/2006/80705, diakses pada 26 November 2016.

Wiggins, S., Introduction to Applied Nonlinear Dynamical Systems and Chaos, Springer-Verlag, New York, 2003

Widowati dan Sutimin, Pemodelan Matematika: Analisis dan aplikasinya, Penerbit Undip Press, Semarang, 2013. 